\title{
Penyuluhan Pengembangan Kreatifitas Perancangan Gim Edukasi Anak di TK Kristen Tunas Kasih Prambanan
}

\author{
Kathryn Widhiyanti ${ }^{{ }^{*}}$, Agnes Karina Prita Atmani ${ }^{2}$ \\ ${ }^{1,2}$ Program Studi Animasi, Institut Seni Indonesia, Yogyakarta \\ Email: ${ }^{*}$ kathryn@isi.ac.id, ${ }^{2}$ agneskarina@isi.ac.id
}

(Naskah masuk: 29 April 2021, direvisi: 03 Mei 2021, diterima: 12 Mei 2021)

\begin{abstract}
Abstrak
Taman Kanak-kanak (TK) Tunas Kasih Prambanan merupakan bagian dari Yayasan Pendidikan Kristen Klaten dan menjadi bagian pelayanan dari GKJ Prambanan Klaten. Proses kegiatan belajar mengajar yang diberikan oleh guru-guru bagi siswa-siswi TK Tunas Kasih yang bertujuan untuk memunculkan karakter masing-masing siswa dan juga menanamkan karakter yang baik untuk para siswa. Aktifitas-aktifitas yang diberikan ke siswa lebih banyak berupa kegiatan yang membuat anak-anak bermain. Permainan akan membuat siswa secara tidak langsung belajar atau mengenal karakter masing-masing. Karakter anak, tentu saja tidak hanya dibentuk/dimunculkan di sekolah. Sekolah hanya membantu para orang tua untuk memunculkan karakter anak-anak. Orang tua selain memberi contoh juga dapat mengemas nasehat-nasehet dalam bentuk permainan. Penyuluhan pengembangan kreatifitas perancangan gim yang dilakukan oleh Tim dari Prodi Animasi ISI Yogyakarta, diharapkan dapat berdiskusi dan berbagi ilmu untuk meningkatkan pengetahuan para orang tua dan guru TK Kristen Tunas Kasih Prambanan
\end{abstract}

Kata Kunci: pengembangan gim, kreatifitas, gim edukasi, karakter anak

\section{Counseling on the Development of Creativity in Designing Children's Educational Games at Tunas Kasih Christian Kindergarten Prambanan}

\begin{abstract}
Tunas Kasih Prambanan Kindergarten is part of the Klaten Christian Education Foundation and is part of the service of GKJ Prambanan Klaten. The process of teaching and learning activities provided by teachers for Tunas Kasih Kindergarten students which aims to bring out the character of each student and also instill good character for the students. The activities given to students are more in the form of activities that make children play. The game will make students indirectly learn or get to know each other's characters. The character of the child, of course, is not only formed / raised in school. Schools only help parents to bring out their children's character. Parents besides giving examples can also package advice in the form of games. Counseling on the development of creativity in game design conducted by the team from the Yogyakarta ISI Animation Study Program, is expected to be able to discuss and share knowledge to increase the knowledge of parents and teachers of the Tunas Kasih Prambanan Christian Kindergarten
\end{abstract}

Keywords: game development, creativity, educational games, children's character

\section{PENDAHULUAN}

Taman Kana-kanan (TK) Kriten Tunas Kasih Prambanan berada dibawah Yayasan Pendidikan Kristen Klaten dan menjadi bagian pelayanan dari GKJ Prambanan Klaten. Sekolah TK Tunas Kasih mulai dirintis pada 19 Januari 1970 oleh Ikatan Wanita Kriten Klaten [1]. Saat ini TK Kristen
Tunas Kasih di kepalai oleh Ibu. Suci Cahyaningsih, S.Pd.AUD. Semula TK Tunas Kasih menempati rumah salah satu warga di dusun Taji, Prambanan, Klaten dan saat ini sudah memiliki gedung sekolah sendiri yang berdiri di tanah kas Desa Taji, Prambanan. Lokasi TK berada di desa yang sejuk dekat dengan persawahan dan rel kereta api. Dengan lokasi 
yang berada di pedesaan TK Tunas Kasih dapat memberikan pelayanan dalam bidang pendidikan untuk warga di sekitar desa Taji.

Siswa-siswi TK Kristen Tunas Kasih, tidak hanya berasal dari keluarga Kristen, rata-rata berasal dari Prambanan khususnya warga desa Taji dan putra-putri dari Jemaat GKJ Prambanan. Pada tahun ajaran ini, peserta didik dari TK Kristen Tunas Kasih ada sekitar 30 siswa untuk kelas TK Kecil dan TK Besar. Bentuk pelayanan pendidikan TK Kristen Tunas Kasih berfokus pada pendidikan karakter anak.

Banyak aktifitas-aktifitas yang diberikan oleh guruguru bagi siswa-siswi TK Tunas Kasih yang bertujuan untuk memunculkan karakter masing-masing siswa dan juga menanamkan karakter yang baik untuk para siswa. Aktifitasaktifitas yang diberikan ke siswa lebih banyak berupa kegiatan yang membuat anak-anak bermain. Permainan akan membuat siswa secara tidak langsung belajar atau mengenal karakter masing-masing.

Guru-guru sebagai pendidik di sekolah TK Tunas Kasih selalu berusaha untuk memberikan metode-metode belajar yang menarik untuk siswa-siswanya. Gim atau permainan, tentu menjadi pilihan oleh para Guru dalam menyampaikan tujuan dari pendidikan di TK Tunas Kasih. Setiap tahun ajaran, Guru TK Kristen Tunas Kasih akan berkreasi untuk mengembangkan atau menciptakan gim-gim yang menarik tetapi juga dapat membantu menyampaikan tujuan dari target belajar yang sudah ditentukan.

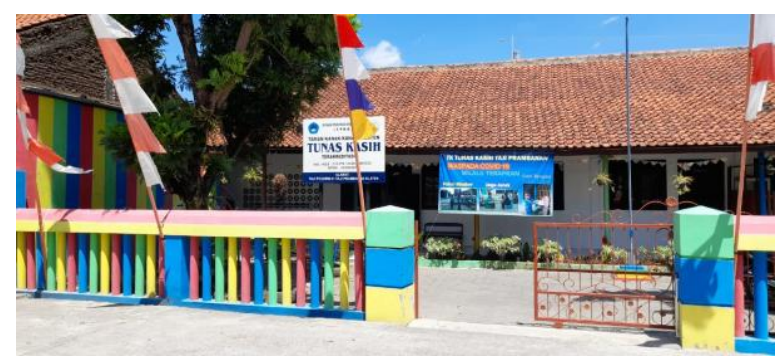

Gambar 1. TK Kristen Tunas Kasih Prambanan Karakter anak, tentu saja tidak hanya dibentuk/dimunculkan di sekolah. Sekolah hanya membantu para orang tua untuk memunculkan karakter anak-anak. Orang tua tentu saja menjadi faktor utama yang dapat menanamkan karakter yang baik untuk anak-anak mereka. Selain memberikan contoh langsung, orang tua akan bertindak kreatif untuk dapat memberikan pendidikan karakter di rumah, salah satunya tentu dengan permainan atau cerita. Penyuluhan ini juga memiliki tujuan agar guru dan orang tua dapat menentukan media yang sesuai dengan pembelajaran yang akan disampaikan dengan memanfaatkan barang-barang yang ada disekitar anak agar tidak tergantung pada barangbarang jadi [2]

\section{METODOLOGI PENELITIAN}

Pengabdian Masyarakat di TK Kristen Tunas Kasih ini dimulai dengan adanya diskusi antara Ibu Kathryn Widhiyanti dengan Kepala Sekolah TK Kristen Tunas Kasih mengenai kebutuhan Guru dan Orang Tua mengenai pengembangan diri dengan tema pendidikan. Ibu Kathryn Widhiyanti bersama Ibu Agnes Karina Pritha, membawa kebutuhan TK Kristen Tunas Kasih yang disertai dengan proposal ke Lembaga Penelitian dan Pengabdian Masyarakat (LPPM) Institut Seni Indonesia Yogyakarta untuk didaftarkan melalui program Pengabdian Masyarakat Penyuluhan.

Program pengabdian Masyarakat dalam bidang penyuluhan LPPM Institut Seni Indonesia Yogyakarta, Pelaksanaan penyuluhan ini dilakukan pada tanggal 19 dan 20 Maret 2020. Dalam pelaksanaannya, Ibu Kathryn Widhiyanti dan Ibu Agnes Karina Pritha dibantu oleh seorang mahasiswa yaitu Ilham Fashihlul Lisan.

Metode yang digunakan dalam penyuluhan seni di TK Kristen Tunas Kasih adalah pemaparan materi, diskusi dan praktek langsung perancangan dan pembuatan gim edukasi untuk anak. Pemaparan materi bertujuan untuk menambah wawasan bagi orang tua mengenai gim-gim anak yang sesuai dengan usia dan manfaat dalam pendidikan. Diskusi dan praktek langsung, diharapkan akan membuat orang tua terbuka dalam menyampaikan pendapat dan masalah-masalah yang dihadapi agar bisa bersama-sama mencari solusinya. Praktik langsung merancang dan membuat gim dengan bahanbahan atau permainan yang sudah ada sebelumnya, bertujuan untuk meningkatkan kreatifitas orang tua dalam membuat permainan untuk anaknya yang sesuai dengan kebutuhan masing-masing anak.

\section{PEMBAHASAN}

Pada tanggal 19 Maret 2020 pelaksanaan kegiatan penyuluhan pengabdian masyarakat untuk TK Kristen mulai dilaksanakan. Kegiatan ini diawali dengan penerjunan Tim Dosen Penyuluhan oleh Tim LPPM kepada Kepala Desa Taji dan TK Kristen Tunas Kasih. Proses penerjunan dilakukan untuk menjalin silaturahmi dan ijin ke Kepala Desa Taji Prambanan jika ada kegiatan berupa penyuluhan dari Institut Seni Indonesia Yogyakarta di TK Kristen Tunas Kasih.

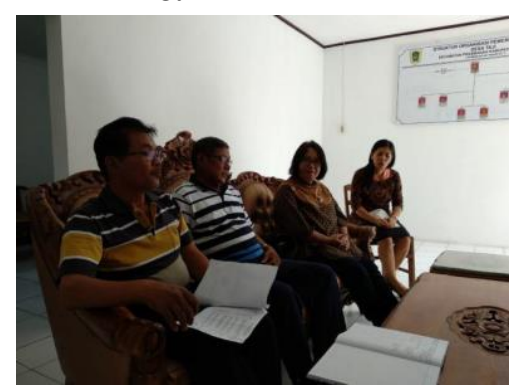

Gambar 2. Penerjunan di Kantor Desa Taji Prambanan

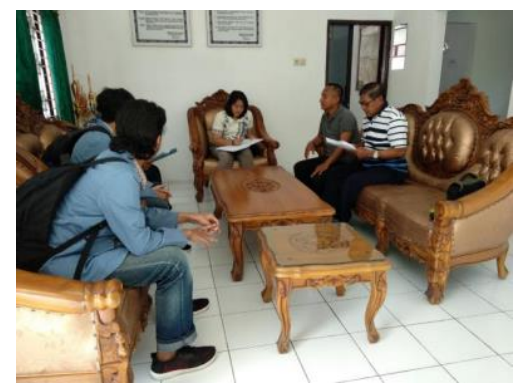


Gambar 3. Penerjunan di Kantor Desa Taji Prambanan

Setelah dilakukan penerjunan, kegiatan penyuluhan langsung dimulai dengan pertemuan Bersama guru TK Tunas Kasih. Pertemuan ini merupakan diskusi antara Tim dari ISI Yogyakarta Bersama Tim Guru TK Tunas Kasih mengenai metode-metode pembelajaran yang dilakukan oleh guru-guru TK Kristen Tunas Kasih. Tim ISI Yogyakarta diajak untuk melihat peralatan-peralatan yang ada di sekolah yang sekiranya bisa dikembangkan untuk sebuah bentuk permainan. TK Kristen Tunas Kasih, memiliki banyak alat dan permainan yang dapat dikembangkan menjadi bentuk permainan baru.

Pada pertemuan ini, membahas mengenai bagaimana proses belajar mengajar yang sudah berjalan di TK Tunas Kasih. Metode yang dipakai adalah metode bermain seperti metode pengajaran untuk anak usia TK pada umumnya. Untuk materi membaca, menulis, dan menghitung (CALISTUNG) memang tidak secara langsung diajarkan dan menjadi indikator keberhasilan siswa di TK Tunas Kasih. Guru-guru menyisipkan proses CALISTUNG dalam permainan, sehingga anak-anak tidak merasakan bahwa sedang belajar. Metode ini sudah sangat baik, namun menjadi tantangan bagi guru-guru untuk menciptakan permainan yang menarik untuk siswasiswi.

Ibu Prita sebagai narasumber, menyampaikan bahwa definisi kreativitas adalah sebuah bentuk imajinasi yang diolah sedemikian rupa sehingga menghasilkan sebuah proses atau sesuatu yang bermanfaat bagi kehidupan orang lain [3]. Proses kreatif ini dapat diperoleh dengan mengamati kegiatan siswa sehari-hari dan memanfaatkan permainan yang sudah dimiliki oleh TK. Di TK Tunas Kasih sudah memiliki banyak media bermain sehingga bisa langsung dimanfaatkan. Misalnya, ada perosotan, terkadang anak-anak berebutan untuk bermain. Hal ini bisa digunakan sebagai bentuk perancangan sebuah gim, kita bisa menyisipkan beberapa pertanyaan baik dengan materi akademik atau hal budi pekerti.

Guru-guru diajak untuk berdiskusi dari perosotan tadi dan diperoleh sebuah alur permainan. Saat anak mau naik perosotan, masing-masing akan diminta mencontohkan untuk bagaimana caranya minta ijin, mencontohkan cara mencuci tangan yang benar, dan mencontohkan kegiatan lainnya yang akan membiasakan anak untuk melakukan kegiatan yang sudah diajarkan sebelumnya.

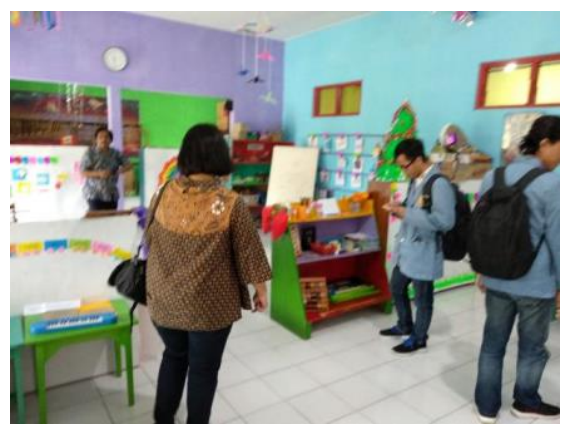

Gambar 4. Kegiatan Diskusi bersama Guru TK Tunas Kasih

Peretemuan berikutnya yaitu tgl 20 Maret 2020, penyuluhan ditujukan untuk orang tua siswa. Materi pada penyuluhan ini terkait dengan pengembangan gim. Ibu Agnes Karina Prita menyampaikan gim edukasi karya mahasiswa ISI Yogyakarta dari Prodi D3 Animasi dengan judul Pick-Up
Hamsa. Game Pick Up Hamsa memberikan edukasi dalam membentuk karakter anak seperti Hamsa yang menyukai kebersihan. Dalam permainan ini, Hamsa akan membersihkan sampah-sampah yang ditemukan dalam perjalanannya menyelamatkan Dewi Saraswati. Game Pick Up Hamsa [4], menjadi contoh bentuk pengembangan kreatifitas yaitu permainan yang dimulai dari sebuah cerita atau karakter sebuah tokoh yang kemudian dibawa menjadi desain sebuah permainan.

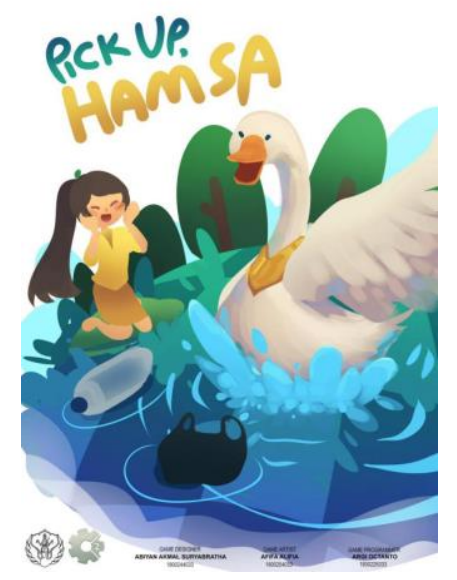

Gambar 5. Game Pick Up. Hamsa

Materi dilanjutkan dengan memberikan beberapa contoh pengembangan gim dari papan permainan (board game) yang sudah sangat dikenal oleh para orang tua, yaitu permainan ulartangga, halma, catur dan ludo. Tujuan perancangan media edukasi boardgame dapat memotivasi aktifitas,kreatifitas, dan sportifitas dalam pengembangan ilmu pengetahuan, keterampilan, dan sikap pada anak-anak usia [5]. Para orang tua dibentuk dalam kelompok dan mulai merancang bentuk pengembangan permainan.

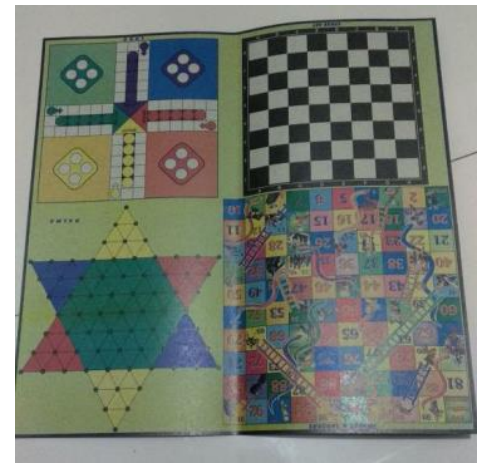

Gambar 6. Papan Permainan Ular Tangga, Catur, Ludo dan Halma

Dari diskusi kelompok ini ternyata, para orang tua dapat mengembangkan gim dari permainan-permainan sederhana yang sudah biasa dimainkan oleh anak-anak. Sebagi contoh ada orang tua yang mengembangkan gim ulartangga dengan menambahkan beberapa bentuk pertanyaan yang harus dijawab anak ketika mendapatkan ular yang membuat Langkah anak mundur. Jika anak bisa menjawab maka anak akan tetap berada diposisinya sekarang. Pertanyaan yang 
diberikan misalnya setelah bangun pagi apa yang harus dilakukan? Jawaban yang diharapkan adalah anak akan melakukan berdoa, merapikan tempat tidur kemudian mandi. Jika hal ini berulang-ulang dilakukan, maka bisa memberikan pemahaman dan menjadi pengetahuan untuk anak.

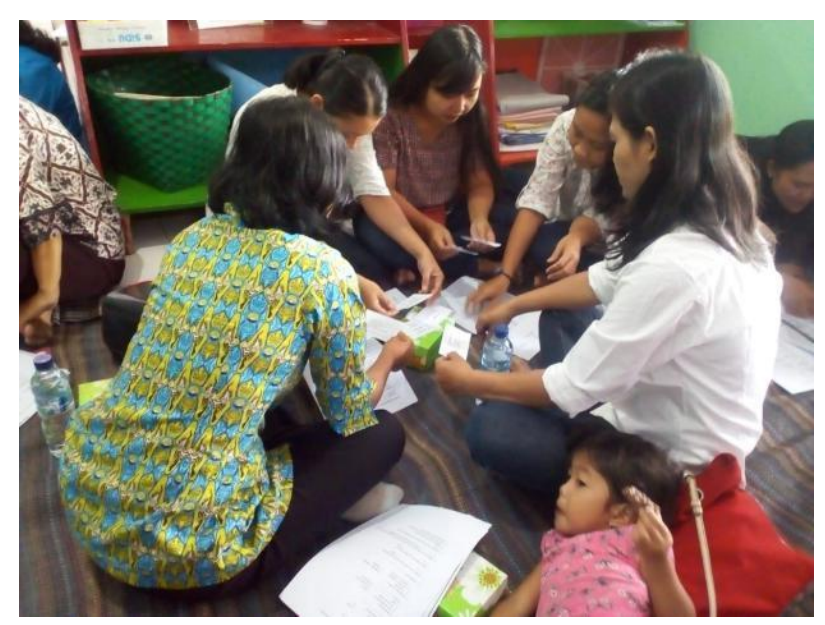

Gambar 7. Suasana Diskusi Orang Tua Siswa

Ibu Kathryn juga menambahkan materi mengenai penerapan game dalam kehidupan sehari-hari. Misalnya, saat anak dapat melakukan sesuatu dengan baik, maka orang tua bisa memberikan reward yang sederhana misalnya stiker yang bisa dikumpulkan kemudian bisa di tukar dengan makanan jika sudah terkumpul beberapa stiker. Konsep-konsep permainan yang mungkin disukai anak-anak juga dapat diterapkan dalam kebiasaan sehari-hari. Namun, dalam penerapan orang tua juga harus memilah-milah gim yang dapat diterapkan. Jangan sampai malah gim yang diadopsi membawa pengaruh negatif untuk anak.

Kegiatan penyuluhan tidak hanya selesai pada tanggal 20 Maret, namun dikarenakan kondisi Pandemi Covid 19, akhirnya Tim ISI Yogyakarta membuka kesempatan untuk diskusi melalui Whats Up Grup (WAG). Dalam diskusi melalui WAG para orang tua membagikan beberapa game yang dilakukan bersama anak-anak di rumah.

Gim Monopoli seperti pada Gambar 9, merupakan contoh Gim yang dikembangkan oleh salah satu orang tua bersama anaknya. Ide kreatif yang diterapkan dalam gim monopoli ini adalah dengan memodifikasi kartu "dana umum" sebagai kartu "perbuatan baik" dan kartu "perbuatan yang tidak baik". Ketika anak mendapatkan salah satu dari kartu tersebut, anak diminta untuk merespon baik denga napa yang dirasakan maupun dengan praktek melakukan. Contoh untuk kartu perbuatan baik yaitu "lakukan salim dan cium tangan untuk ayah, lalu bisa maju 2 kotak". Ide ini juga dikembangkan untuk pertanyaan-pertanyaan akademik, misalnya penjumlahan, pengurangan atau pengenalan huruf.

Kegiatan pengabdian masyarakat ini, ternyata memberikan manfaat dan pengetahuan kepada orang tua untuk berkreatifitas membuat aktifitas untuk anak-anak. Manfaat ini terasa sekali karena sehari setelah penyuluhan ternyata ada himbauan untuk stay at home, yang ternyata membuat banyak orang tua kebingungan untuk memberikan kegiatan anak yang menyenangkan, namun tetap ada unsur edukasiya.

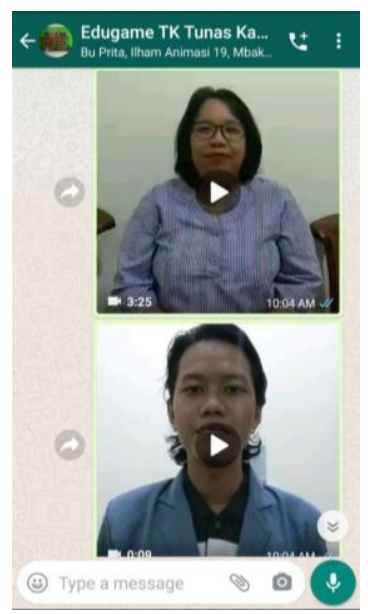

Gambar 8. WAG untuk Diskusi orang tua,guru dan tim penyuluh

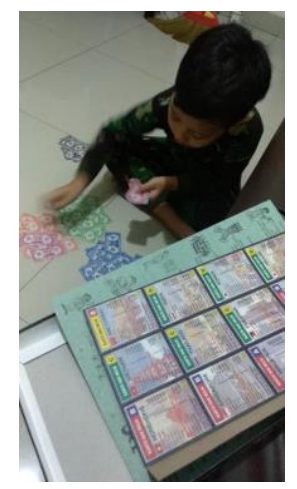

Gambar 9. Foto pengembangan gim oleh orang tua dan anak di rumah

\section{KESIMPULAN}

Setelah selesai melaksanakan kegiatan penyuluhan pengembangan kreatifitas perancangan gim edukasi untuk TK Kriten Tunas Kasih. Tim penyuluh ISI Yogyakarta beserta guru-guru TK melakukan evaluasi dan berdiskusi dan disimpulkan bahwa kegiatan penyuluhan mengenai pengembangan kreatifitas dapat dilakukan lagi dengan materimateri yang lebih menarik yang bermanfaat bagi guru, orang tua dan siswa sendiri. Untuk materi perancangan kreatifitas ini ternyata memberikan manfaat ketika libur sekolah dan ternyata ada arahan untuk stay at home selama pandemic Covid-19. Selain itu TK Kristen Tunas Kasih juga akan merencanakan untuk kunjungan ke ISI Yogyakarta khususnya Prodi D3 Animasi untuk mengetahui proses belajar dan penciptaan gim oleh mahasiswa.

Selain itu, TK Kristen Tunas Kasih Prambanan juga membuka kesempatan jika ada bentuk-bentuk kerjasama yang lain seperti penelitian yang melibatkan guru-guru dan anakanak. TK Kristen Tunas Kasih juga berharap tidak hanya dari bidang gim saja yang melakukan penyuluhan. Bagi Dosen, LPPM dan mahasiswa ISI Yogyakarta, kegiatan pengabdian 
ini merupakan bentuk berbagi pengetahuan dengan masyarakat umum dan dapat langsung diterapkan.

\section{REFERENSI}

[1] Y. Klaten, “Taman Kanak-kanak (TK) Tunas Kasih Prambanan."

https://www.ypkklaten.or.id/tk/tktunaskasih.php (accessed Apr. 21, 2021).

[2] C. N. Aulina, V. Rezania, and E. Destiana, "Pengabdian kepada masyarakat melalui pendampingan bagi guru pos paud," vol. 3, no. 2, pp. 41-45, 2018.

[3] H. Haryanto, I. Gamayanto, S. Novianto, and A. Z. Fanani, "Penyuluhan Peluang Industri Kreatif di bidang Game Digital bagi Generasi Muda untuk Siswa SMA Negeri 3 Semarang," vol. 4, no. 1, pp. 36-42, 2021.

[4] A. (Institut S. I. Y. Octanto, "Pick Up Hamsa," 2020. https://www.youtube.com/watch?v=Pxzxx5QrqtA (accessed Apr. 23, 2021).

[5] S. D. M. D. Gusranda, Ir. Drs. Heldi, M.Si., Ph.D, Dini Faisal, "PERANCANGAN MEDIA EDUKASI BOARD GAME 'INDOING' PEMBELAJARAN
BAHASA INGGRIS PADA ANAK USIA 6- 12

TAHUN," 2018. 